\title{
Hybrid photocatalysts for the degradation of trichloroethylene in air
}

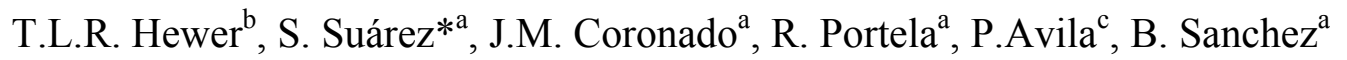 \\ ${ }^{a}$ CIEMAT-PSA Environmental Application of Solar Radiation Unit, Avda. Complutense 22, 28040, Madrid,Spain \\ ${ }^{b}$ Instítuto de Química, Universidade de São Paulo-USP, C.P. 26077, CEP 05513-000, São Paulo, Brazil \\ ${ }^{c}$ Institute for Catalysis and Petrochemistry, C/ Marie Curie 22, Madrid 28049, Spain \\ *Corresponding author.Tel: +3491346 6177, Fax : +34913466037e-mail: silvia.suarez@ciemat.es
}

\begin{abstract}
Hybrid photocatalysts based on an adsorbent $\mathrm{SiMgOx}$ and a photocatalyst $\mathrm{TiO}_{2}$ were developed in a plate shape. The ceramic surface was coated with $\mathrm{TiO}_{2}$ by the slip-casting technique. The effect of the support in the photocatalytic degradation of trichloroethylene (TCE) was analyzed by modifying $\mathrm{TiO}_{2}$ loading and the layer thickness. Photocatalysts were characterised by $\mathrm{N}_{2}$ adsorption-desorption, mercury intrusion porosimetry, SEM, UV-vis spectroscopy and XRD. A direct relationship between the $\mathrm{TiO}_{2}$ content and the photocatalytic activity was observed up to three layers of $\mathrm{TiO}_{2}(0.66 \mathrm{wt} . \%)$. Our results indicate that intermediate species generated on the $\mathrm{TiO}_{2}$ layer can migrate through relatively long distances to react with the $\mathrm{OH}^{-}$surface groups of the support. By increasing the $\mathrm{TiO}_{2}$ loading of the photocatalyst two effects were observed: trichloroethylene conversion is enhanced, while the efficiency of the oxidation process is decreased at expenses of increasing the selectivity to $\mathrm{COCl}_{2}$ and dichloroacetylchloride (DCAC). The results are discussed in terms of the layer thickness, $\mathrm{TiO}_{2}$ amount, TCE conversion and $\mathrm{CO}_{2}, \mathrm{COCl}_{2}$ selectivity.
\end{abstract}

Keywords: Photocatalysis, $\mathrm{TiO}_{2}$, sepiolite, hybrid photocatalyst, trichloroethylene. 


\section{Introduction}

Nowadays photocatalysis is a well-established technology for the abatement of pollutants, either in aqueous media or in the gas phase. $\mathrm{TiO}_{2}$ is the most common material used in semiconductor photocatalyst because it is widely available at low prices and it possesses excellent photocatalytic properties. Generally, $\mathrm{TiO}_{2}$ suspensions are preferred over supported catalysts because of the higher reaction rate of the former. For industrial applications, however, the development of supported photocatalysts is crucial. The immobilization of $\mathrm{TiO}_{2}$ photocatalyst on a support avoids expensive filtration processes and the lost of the active component [1]. For this reason, the synthesis of immobilised photocatalytic materials is receiving a great deal of attention by both scientists and engineers [2][3]. Different materials such as glass, plastics and fibres are used as supports [4], [5]. A more interesting approach consists in preparing hybrid photocatalysts, where adsorption and photocatalytic properties are combined, thus inducing a synergism towards the abatement of pollutants [6]. Physisorption of pollutants on the adsorbent part of the photocatalyst and their subsequent diffusion to the $\mathrm{TiO}_{2}$ active sites results in an increase of the photocatalytic efficiency of this hybrid photocatalyst compared with traditional ones. Adsorbent with high surface area such as silica beads [7], pillared clays [8], mesoporous materials [9] and activated carbons [10] [11] have been studied. The interaction between the adsorbent and the pollutant has to be controlled to allow pollutant diffusion to the interface between the adsorbent and the photoactive material.

Sepiolite is a natural magnesium silicate with a fibrous structure characterised by a high surface area, porosity and the capacity to include high quantity of water in the structure. This compound has been used in many applications [12] [13] [14]. Although it has been suggested that it can play a role in the diffusion of oxygen species and hydrogen spillover [15] [16] the role of sepiolite is not fully understood.

On the other hand the diffusion through the air and solid phase of the $\mathrm{OH}$ radicals generated on illuminated $\mathrm{TiO}_{2}$ has been reported for $\mathrm{TiO}_{2}$ thin films on conventional supports [17]. Remote photodegradation of self-assembled monolayers of aliphatic chains anchored to an 
inert silicon surface and located at $20 \mu \mathrm{m}$ away from the $\mathrm{TiO}_{2}$ microdomains has been reported, demonstrating the diffusion ability of oxidizing species on the $\mathrm{TiO}_{2}$ surface [18]. Remote oxidation of organic dyes separated from a $\mathrm{TiO}_{2}$-coated plate by a small gap has also been proved [19].

The high quantum yield for trichloroethylene (TCE) degradation over $\mathrm{TiO}_{2}$, which has been associated with the participation of chlorine [20] and hydroxyl radicals [21] as oxidative species in the reaction mechanism, has prompted the wide use of this compound as a model pollutant in photocatalytic studies [22] [23] [24]. The global oxidation pathway in the presence of water vapour is depicted in Eq 1:

$$
\mathrm{C}_{2} \mathrm{HCl}_{3}+\frac{3}{2} \mathrm{O}_{2}+\mathrm{H}_{2} \mathrm{O} \rightarrow 2 \mathrm{CO}_{2}+3 \mathrm{HCl}
$$

Nevertheless, the reaction is not as simple as represented in Eq.1 and side reactions with the formation of different chlorinated products have been reported. Dichloroacetyl chloride (DCAC), phosgene $\left(\mathrm{COCl}_{2}\right)$ and molecular chlorine besides $\mathrm{CO}$ have been detected depending on operating conditions such as residence time and the water vapour partial pressure [25]. The complete mineralization can not be accomplished in the absence of moisture and the formation of $\mathrm{COCl}_{2}$, a very toxic compound, in addition to $\mathrm{CO}_{2}$ is produced according to Eq 2:

$$
\mathrm{C}_{2} \mathrm{HCl}_{3}+\frac{3}{2} \mathrm{O}_{2} \rightarrow \mathrm{COCl}_{2}+\mathrm{HCl}+\mathrm{CO}_{2}
$$

In a previous study, plate shaped $\mathrm{TiO}_{2}-\mathrm{SiMgOx}$ hybrid photocatalysts were prepared and tested for TCE degradation. $\underline{\mathrm{TiO}}_{2} \underline{\text { was }}$ used in two different forms: in one case silicate and titania were mixed and extruded together; in a different approach, $\mathrm{TiO}_{2}$ thick films were coated on previously extruded ceramic plates [26]. Materials obtained in both ways are referred to as incorporated and coated materials, respectively. The "corncob" like structure of $\mathrm{TiO}_{2}-\mathrm{SiMgOx}$ incorporated plates favoured the mineralization of TCE. Intermediate species photocatalytically generated in the $\mathrm{TiO}_{2}$ nanoparticles may migrate through the adsorbentphotocatalyst interface to finally react with the numerous $\mathrm{OH}^{-}$surface groups and adsorbed water molecules of the silicate. On coated samples, the migration through the $\mathrm{TiO}_{2}$ thick films was supposed to be hindered.

Based on this working hypothesis, the aim of this work is to understand the role of the silicate as an active material in the photocatalytic process. Thus, sepiolite plates were coated with 
different number of $\mathrm{TiO}_{2}$ layers from one to four modifying the $\mathrm{TiO}_{2}$ amount and the layer thickness. The gap between the illuminated external surface where the photocatalytic process takes place and the interface where the reaction between intermediate species and $\mathrm{OH}$ - groups occurs has been modulated. 


\section{Experimental}

\subsection{Catalyst preparation}

Magnesium silicate (Tolsa S.A) was used to prepare the ceramic plates. The composition of the magnesium silicate, expressed as oxides, was $\mathrm{SiO}_{2}: 59.50 \%, \mathrm{MgO}: 17.55 \%, \mathrm{Al}_{2} \mathrm{O}_{3}: 6.26 \%$, CaO: 2.36 wt. $\%, \mathrm{Fe}_{2} \mathrm{O}_{3}: 1.84$ wt. $\%, \mathrm{Na}_{2} \mathrm{O}: 0.53$ wt.\%, $\mathrm{K}_{2} \mathrm{O}: 1.73$ wt.\%. The powder samples were mixed and kneaded with water until a ceramic dough with the optimal plasticity was obtained [27]. The plates were obtained by extrusion using a specifically designed die. Fresh samples were dried at room temperature for seven days, then at $110^{\circ} \mathrm{C}$ for 24 hours and finally heat treated at $800^{\circ} \mathrm{C}$ for 4 hours. The resulting plates presented the following dimension: 8.0 $\underline{\mathrm{x} 2.9 \times 0.25 \mathrm{~cm} \text { (length } \mathrm{x} \text { width } \mathrm{x} \text { thickness). }}$.

Commercial $\mathrm{TiO}_{2}$ (G-5 Millenium) with purity higher than $98 \%$ and a sulphate content between 0.8-1.7 wt.\%, $\mathrm{P}_{2} \mathrm{O}_{5}<0.4$ wt.\% and $\mathrm{Na}_{2} \mathrm{O}$ and $\mathrm{K}_{2} \mathrm{O}<0.01$ wt.\% was selected to prepare the aqueous suspension. A water dispersion of $\underline{\mathrm{TiO}}_{2}\left(30 \mathrm{~g} \mathrm{~L}^{-1}\right)$ acidified with $1 \mathrm{M}$ $\mathrm{HNO}_{3}$ was prepared by prolonged sonication to improve the dispersion in the aqueous media. The $\mathrm{SiMgO}_{\mathrm{x}}$ plates treated at different temperatures were immersed in the $\mathrm{TiO}_{2}$ suspension by the slip casting technique at a constant rate of $3 \mathrm{~mm} \cdot \mathrm{s}^{-1}$. Four samples were prepared by varying the number of coatings from one to four, drying the samples after each coating at $100^{\circ} \mathrm{C}$ for 1 hour. The materials were finally heat treated at $500^{\circ} \mathrm{C}$ for $4 \mathrm{~h}$. The surface of the support covered by $\mathrm{TiO}_{2}$ was around $20.0 \mathrm{~cm}^{2}$. The photocatalysts were named as SiTi-x where $\mathrm{x}$ indicates the number of $\mathrm{TiO}_{2}$ layers.

\subsection{Physicochemical characterization}

The specific surface area $\left(\mathrm{S}_{\mathrm{BET}}\right)$ of the samples was calculated from nitrogen adsorption at $-196^{\circ} \mathrm{C}$ determined with a Carlo Erba Sorptomatic 1800, outgassing the samples overnight using oil-diffuser and rotatory pumps at $300^{\circ} \mathrm{C}$ to a pressure of $<1.3310^{-2} \mathrm{~Pa}$ to ensure a dry clean surface, free from any loosely bound adsorbed species. The pore volumes were analyzed by use of Mercury Intrusion Porosimetry (MIP) using CE Instruments Pascal 
$140 / 240$ porosimeter, after drying the samples at $150^{\circ} \mathrm{C}$ overnight. The total pore volumes were determined by combinations of nitrogen adsorption and mercury intrusion analysis.

$\mathrm{X}$-ray diffraction (XRD) patterns of ground samples of the monolithic catalyst were recorded on a Phillips PW1710 powder diffractometer using CuK $\alpha$ radiation: $\lambda=0.154 \mathrm{~nm}$, sampling data every $0.02^{\circ}(2 \theta)$ at an acquisition rate of $2 \mathrm{~s} /$ step. The mean $\mathrm{TiO}_{2}$ particle size was determined from Scherrer's equation with the normal assumption of spherical crystallites. The anatase phase content was determined from peak intensity of the most intense diffraction peak, (101) peak at $25.4^{\circ}$. UV-Vis absorption spectra of the plates were collected with a LAMBDA 950 UV-Vis-NIR spectrophotometer between 2500-300 nm wavelength with 10 nm step.

Scanning electron microscopy and energy dispersive X-ray spectroscopy studies were performed in a Zeiss DSM 960 Digital Scanning Microscope with a $\mathrm{Si} / \mathrm{Li}$ detector and a $\mathrm{Be}$ window of $7 \mu \mathrm{m}$ thickness, coupled with an analyzer of dispersive energies EXD Link eXL with a $25 \mathrm{keV}$ electron beam and a take-off angle of $45^{\circ}$. Samples were coated with a conductive layer of graphite to minimize charging effects.

\subsection{Photocatalytic tests}

The photocatalytic oxidation of trichlotoethylene (TCE) was studied in a continuous plug flow gas-phase flat photoreactor. The photoreactor with external dimensions $120 \mathrm{x} 50 \mathrm{x}$ $10 \mathrm{~mm}$ (length $\mathrm{x}$ wide $\mathrm{x}$ thickness) was made of stainless steel except for one face where a window of $27 \mathrm{~cm}^{2}$, made of pyrex glass, was placed for the photocatalyst illumination provided by two UVA Philips TL-8W/05 fluorescent lamps with a maximum emission at 365 $\mathrm{nm}$ wavelength and light intensity $4.4 \mathrm{~mW} \cdot \mathrm{cm}^{-2}$ with a Cole Parmer Radiometer VLX3W. A gas mixture of TCE and air was prepared using gas cylinder of TCE/ $\mathrm{N}_{2}$ (Air Liquide, 500 ppm) and compressed air free of water and $\mathrm{CO}_{2}$. The flow rate was controlled by using electronic mass flow controllers. The TCE concentration was kept at $90 \mathrm{ppm}$, and the total gas flow between 240 to $700 \mathrm{ml} \cdot \mathrm{min}^{-1}$. The gas composition was monitored continuously using a FTIR Thermo-Nicolet 5700 spectrometer, provided with a temperature controller multiple reflection gas cell (optical path $2 \mathrm{~m})$ maintained at $110^{\circ} \mathrm{C}$. Gas cylinders of $\mathrm{CO}_{2}(100 \mathrm{ppm}$ Air Liquid) and $\mathrm{COCl}_{2}$ (50 ppm Air Liquid) were used as references to determine the concentration of these compounds during the photocatalytic tests. 


\section{Results and Discussion}

The main characteristics of the hybrid photocatalysts based on sepiolite and covered with different amounts of $\mathrm{TiO}_{2}$ are collected in Table 1. The $\mathrm{TiO}_{2}$ concentration was set between 0.32 to $0.75 \mathrm{wt} . \%$.. A photograph of the silicate plate used as support and after deposition of four layers of $\mathrm{TiO}_{2}$ is shown in Figure 1. The method used for $\mathrm{TiO}_{2}$ deposition ensures the formation of a homogeneous semitransparent film totally covering the surface. $\mathrm{TiO}_{2} \mathrm{G}-5$ treated at $500^{\circ} \mathrm{C}$ presented a BET area of $152 \mathrm{~m}^{2} \mathrm{~g}^{-1}$ and an average crystal size of $16 \mathrm{~nm}$. The sepiolite selected for this study and treated at $800^{\circ} \mathrm{C}$ has a meso-macro structure with a total pore volume of $0.52 \mathrm{~cm}^{3} \mathrm{~g}^{-1}$ and a mean pore diameter centred at $40 \mathrm{~nm}$ [26]. This structure, where macropores are generated by packing of the sepiolite fibres allows the fixation of $\mathrm{TiO}_{2}$ in its surface. The BET area of the material treated at $500^{\circ} \mathrm{C}$ is larger than that of the sample treated at $800{ }^{\circ} \mathrm{C}, 126 \mathrm{~m}^{2} \mathrm{~g}^{-1}$ vs $68 \mathrm{~m}^{2} \mathrm{~g}^{-1}$. Nevertheless, the photocatalytic activity of the latter sample is higher than that of the one treated at $500^{\circ} \mathrm{C}$, at the same $\mathrm{TiO}_{2}$ loading [26]. The high porosity of the support treated at low temperature results in the incorporation of $\mathrm{TiO}_{2}$ inside the porous structure; those sites are not accessible to the UV radiation photons, lowering thus the photocatalyst efficiency. Thus, the selected temperature for the support treatment was $800^{\circ} \mathrm{C}$. Due to the low $\mathrm{TiO}_{2}$ amount, modifications of textural properties were not observed with increasing the number of layers. The adsorption capacity measured in dynamic conditions was $2.2 \mu \mathrm{mol}_{\mathrm{TCE}} / \mathrm{g}_{\mathrm{SiMgOx}}$, using a total flow of $300 \mathrm{~mL} \mathrm{~min}^{-1}$ and $90 \mathrm{ppm}$ TCE concentration.

Figure 2 depicts the variation of the $\mathrm{TiO}_{2}$ loading after consecutive layer deposition and the calculated arithmetic mean value for the SiTi-x composites. A progressive decrease of the $\mathrm{TiO}_{2}$ loading with each deposition was observed. During the first coating around $0.27 \mathrm{wt} . \%$ of $\mathrm{TiO}_{2}$ was taken, but only 0.15 wt.\% was fixed in the third step. These results suggest that the porous structure of the adsorbent was progressively filled with titania particles. When the number of layers was above four, the formation of flakes on the surface with poor adherence to the substrate was observed. 
The $\mathrm{TiO}_{2}$ G5 sample treated at $350^{\circ} \mathrm{C}, 500^{\circ} \mathrm{C}$ and $800^{\circ} \mathrm{C}$ was characterised by XRD. The diffractograms are shown in Figure 3. $\underline{\mathrm{TiO}}_{2}$-anatase was the only crystalline phase detected. As expected, an increase of the crystal size from $11 \mathrm{~nm}$ to $47 \mathrm{~nm}$ was attained when the temperature increased form $350^{\circ} \mathrm{C}$ to $800^{\circ} \mathrm{C}$. The temperature selected for the final treatment of the coated materials was $500^{\circ} \mathrm{C}$ since it yields a large surface area and a particle size of 16 $\mathrm{nm}$ improving the immobilization of $\mathrm{TiO}_{2}$ onto the support.

In order to analyse the thickness of the $\mathrm{TiO}_{2}$ layer, $\mathrm{SEM}$ analyses were performed for all the samples. Because of the ceramic nature of the support the $\mathrm{TiO}_{2}$ layer can be easily detached from the surface during the polished process. Then, a sandwich like structure with a resin between two pieces of the sample was used to fix the $\mathrm{TiO}_{2}$ coating on the surface. Once the resin was dried, the face selected for the analysis was polished. A SEM micrograph of the plate's cross section along to the $\mathrm{TiO}_{2}$ line profile for the sample prepared with four $\mathrm{TiO}_{2}$ layers is shown in Figure 4a. From the left part of the micrograph to the right the different components of the composite can be distinguished: silicate, $\mathrm{TiO}_{2}$ layer, resin (black zone in the middle), $\mathrm{TiO}_{2}$ layer and silicate. The line profile showed around $35 \mu \mathrm{m}$ and $70 \mu \mathrm{m}$ titanium rich areas with a mean layer thickness around $10 \mu \mathrm{m}$ (see Figure 4b). Analyses of twenty different regions give us an estimation of the mean layer thickness of the each sample. From the results shown in Table 1 it can be observed that the thickness of the layers varies from 1 to $10 \mu \mathrm{m}$. After deposition of four $\mathrm{TiO}_{2}$ layers, the fibrous structure of the silicate cannot be distinguished at composite external's surface. Only sphere shaped particles due to $\mathrm{TiO}_{2}$ aggregates covering the surface are observed, $80 \%$ of the particles displaying sizes between 120-320 $\mathrm{nm}[26,28]$.

The reflectance spectra obtained by UV-vis-NIR spectroscopy for sepiolite, $\mathrm{TiO}_{2}$, and SiTi-x photocatalysts are depicted in Figure 5. Bands centered at $1400 \mathrm{~nm}, 1910 \mathrm{~nm}$ and $2300 \mathrm{~nm}$ were detected in the sepiolite. Framework silicates such as quartz have no prominent absorption features in the UV-vis NIR [29]. The bands at $1400 \mathrm{~nm}$ and $1900 \mathrm{~nm}$ can be ascribed to contributions from vibrational combination and overtones of molecular water contained in the material. The spectrum is characteristic of a water rich material showing an intense absorption band at $1900 \mathrm{~nm}$ due to the combination of the $\mathrm{H}-\mathrm{O}-\mathrm{H}$ bending and $\mathrm{O}-\mathrm{H}$ stretching modes [30] [31]. The structure of the sepiolite with channels between the Si and 
$\mathrm{Mg}$ sheet in tetrahedral and octahedral coordination allows the incorporation of a significant amount of water in the channels. Less pronounced absorption peaks also appear at $1400 \mathrm{~nm}$ and $2300 \mathrm{~nm}$. The band at $1400 \mathrm{~nm}$ is the typical first overtone of the O-H stretch. Moreover the band at $2300 \mathrm{~nm}$ is the combination of $\mathrm{Mg}-\mathrm{OH}$ bending, $\mathrm{O}-\mathrm{H}$ stretching combination and $\mathrm{Al}-\mathrm{OH}$ bend in minor proportion. Two bands can be observed in the visible region, at $430 \mathrm{~nm}$, $500 \mathrm{~nm}$, probably due to the presence of iron in the sample [32]. Bands at $2100 \mathrm{~nm}$ and 2200 $\mathrm{nm}$ may be assigned to carbonates present in the magnesium silicate.

In Figure $5 \mathbf{b}$ a magnification of the region between $300-500 \mathrm{~nm}$ is represented. At $300 \mathrm{~nm}$ the reflectance of $\mathrm{TiO}_{2}$ containing samples was closed to zero because of $\mathrm{TiO}_{2}$ band-gap absorption. At this point sepiolite reflects around $20 \%$ of the radiation. Differences on the reflectance of SiTi-x composites with the number of coatings were detected at wavelength above this value. The reflectance obtained at $400 \mathrm{~nm}$ wavelength with the number of coatings are summarised in Table 1 . The surface of sepiolite was progressively covered with $\mathrm{TiO}_{2}$ particles increasing the reflectance lineally with the $\mathrm{TiO}_{2}$ amount from $28.9 \%$ to $50.0 \%$ for

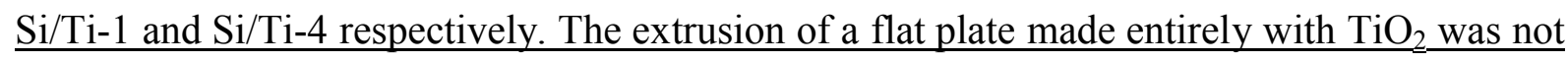
possible, and the presence of a binder such as sepiolite is required. Nevertheless, the spectra $\underline{\text { of } \mathrm{TiO}_{2}} \underline{\mathrm{G}-5}$ fresh powders sample was recorded as a reference point using a powdered sample holder. A reflectance of $90 \%$ at $400 \mathrm{~nm}$ was obtained. The strong increase compared to $\mathrm{Si} / \mathrm{Ti}-$ 4 was associated to the differences in the physico-chemical characteristic of the materials used. 


\section{Photocatalytic activity results}

In order to detect variations in the selectivity of the reaction products, photocatalytic tests were carried out in the absence of water vapour. The influence of the $\mathrm{TiO}_{2}$ loading, which varies with the number of coatings, in the TCE conversion with the total gas flow was investigated. In Figure 6 the TCE conversion as well as the amount of the reaction products detected in the outlet are shown. By lowering the contact time, a decrease of the photocatalytic activity, is observed in accordance with previous results [26]. The results showed that at $300 \mathrm{~mL} \mathrm{~min}^{-1}$ all samples except Si/Ti-1 reached a $90 \%$ of TCE conversion. As expected, higher $\mathrm{TiO}_{2}$ amount yields faster reaction rates at high gas flow. For Si/Ti-1,

$\underline{\mathrm{Si} / \mathrm{Ti}-2 \text { and } \mathrm{Si} / \mathrm{Ti}-3 \text { reaction rate constant values of } 0.58,1.13 \text { and } 1.49 \mu \mathrm{mol} \mathrm{s} \mathrm{cm}^{-2} \text { was }}$ reached at $500 \mathrm{~mL} \mathrm{~min}^{-1}$ respectively (referred to the geometric area of the support of 22.5 $\mathrm{cm}^{2}$ ). Nevertheless a progressive increase of the rate with the total flow was observed for

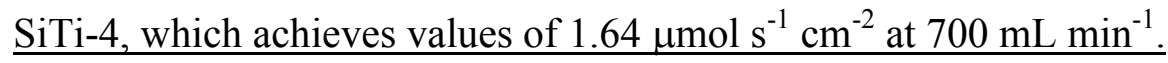

A strong influence of the $\mathrm{TiO}_{2}$ amount in the activity at low $\mathrm{TiO}_{2}$ concentration was observed. Thus, an increase of the $\mathrm{TiO}_{2}$ content from $0.32 \mathrm{wt} . \%$ to $0.55 \mathrm{wt} \%$ resulted in an increase of the TCE conversion around $40 \%$. On the other hand only a slight influence of the $\mathrm{TiO}_{2}$ content on the photocatalytic activity was observed for SiTi-3 and SiTi-4. As a matter of fact, these samples display similar performance being the most active of the series. The deposition of four layers of $\mathrm{TiO}_{2}$ is near the highest loading that still permits an effective use of the UV radiation. Above $10 \mu \mathrm{m}$ the formation of flakes on the $\mathrm{TiO}_{2} \underline{\text { layer took place. Then, the }{ }_{\mathrm{TiO}}} \underline{2}_{2}$ layer was flaking, avoiding the deposition of higher $\mathrm{TiO}_{2} \underline{\text { amount. }}$

For comparative purposes a sample prepared with $\mathrm{TiO}_{2}$ sol-gel with 4 layers on a borosilicate plate [33] was tested under similar conditions. A 35\% of TCE conversion was attained at 300

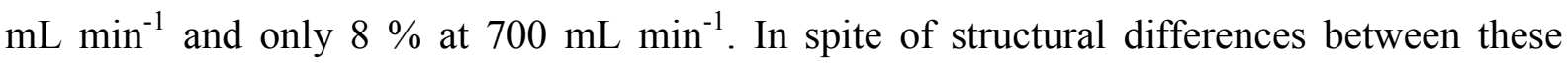
systems such as particle size, BET area or $\mathrm{TiO}_{2}$ loading, the superior catalytic performance of the hybrid composites reveals the advantage of the combination of adsorption and photocatalytic properties in a single material, by allowing the treatment of a large gas volume at relative high concentration of pollutant. 
A decrease of the $\mathrm{CO}_{2}$ and $\mathrm{COCl}_{2}$ amount with contact time was also observed (Figure $6 \mathrm{~b}$ and c) with a slight increase in the formation of DCAC, except for Si/Ti-1 where the DCAC was close to zero. According to Blake et al, the formation of $\mathrm{DCAC}$ and $\mathrm{COCl}_{2}$ can be considered as consecutive reactions [25]. Thus, longer residence times favours the reaction of

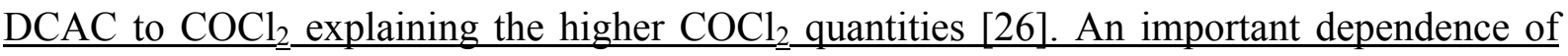
the $\mathrm{COCl}_{2}$ concentration with $\mathrm{TiO}_{2} \underline{\text { loading was observed. }}$

The calculation of the $\mathrm{CO}_{2}$ and $\mathrm{COCl}_{2}$ selectivity should included all the reaction products observed in the reaction. Taking into account that in our case the main reaction products detected where $\mathrm{CO}_{2}$ and $\mathrm{COCl}_{2} \underline{\text { the selectivity to } \mathrm{CO}_{2}} \underline{\text { and } \mathrm{COCl}_{2}} \underline{\text { was estimated according the }}$ carbon balance shown in Eq. 1 and Eq. 2 . Thus, the $\mathrm{CO}_{2} \underline{\text { selectivity was calculated according }}$ to the following equation:

$S_{\mathrm{CO}_{2}}=\frac{C \mathrm{O}_{2}}{\left(T C E_{\text {inlet }}-T C E_{\text {outlet }}\right) \cdot 2} \cdot 100$

These data are shown in Figure 7. The $\mathrm{CO}_{2}$ selectivity decrease in the following order: SiTi$1>>$ SiTi-2 $>$ SiTi-3 $>$ SiTi-4 and the $\mathrm{COCl}_{2}$ selectivity follows the opposite trend. Although SiTi-4 sample was the most active material in terms of conversion, it was also the one that displayed the highest selectivity to $\mathrm{COCl}_{2}$ at the lowest residence time.

The selectivity to $\mathrm{CO}_{2}, \mathrm{COCl}_{2}$ at $90 \%$ TCE conversion (total flow of $300 \mathrm{~mL} \mathrm{~min}{ }^{-1}$ ) was analysed. As the amount of $\mathrm{TiO}_{2}$ increases with the number of layers, the selectivity to $\mathrm{CO}_{2}$ decreases; on the contrary a higher selectivity to $\mathrm{COCl}_{2}$ was observed. These results outline the key role that the interface between the two materials plays in the TCE mineralization. A short distance between the external surface of the $\mathrm{TiO}_{2}$ layer where the photocatalytic reaction occurs and the substrate, favours $\mathrm{CO}_{2}$ formation.

Blake et al. proposed that the reaction proceeds through a DCAC intermediate (Eq. 4) [34]. Then, DCAC reacts to produce the different reaction products. One possible reaction is the formation of $\mathrm{COCl}_{2}$ as shown in Eq. 5. A direct oxidation pathway has also been proposed based on the fact that the oxidation of DCAC in air produces a different proportion of products than that observed during the oxidation of TCE [25]. As it was explained before, 
TCE mineralization reaction in the absence of water vapour produces a large quantity of $\mathrm{COCl}_{2}$. But according Eq 6, $\mathrm{COCl}_{2}$ can undergo hydrolysis reaction in the absence of light to produce $\mathrm{CO}_{2}$. Complete and quantitative hydrolysis of $\mathrm{COCl}_{2}$ to $\mathrm{CO}_{2}$ with activated carbon pellets has been achieved by these authors.

$$
\begin{aligned}
& \mathrm{C}_{2} \mathrm{HCl}_{3}+\frac{1}{2} \mathrm{O}_{2} \rightarrow \mathrm{C}_{2} \mathrm{HCl}_{3} \mathrm{O} \\
& \mathrm{C}_{2} \mathrm{HCl}_{3} \mathrm{O}+\frac{1}{2} \mathrm{O}_{2} \rightarrow \mathrm{COCl}_{2}+\mathrm{HCl}+\mathrm{CO} \\
& \mathrm{COCl}_{2}+\mathrm{H}_{2} \mathrm{O} \rightarrow \mathrm{CO}_{2}+2 \mathrm{HCl}
\end{aligned}
$$

When the contact time was below $0.6 \mathrm{~s}$ (obtained at $500 \mathrm{~mL} \mathrm{~min}^{-1}$ ), TCE could hardly adsorbed on the actives sites and a decrease $\underline{\text { in the concentration of all reaction products was }}$ observed. Above this value, adsorbed DCAC has enough time to react with oxygen to produce $\mathrm{COCl}_{2}$ and $\mathrm{CO}_{2}$. The results showed in Figure 7 indicate that high $\mathrm{TiO}_{2}$ loading due to larger thickness) produced an increase in the $\mathrm{COCl}_{2}$ formation probably because the reaction with the $\mathrm{OH}$ surface groups of the adsorbent was not favoured. Nevertheless, for low $\mathrm{TiO}_{2}$ layer thickness, the migration of the reaction intermediates and the subsequent reaction with the $\mathrm{OH}$ groups of the silicate was promoted. These data support previous result where it was proposed that incorporated hybrid photocatalysts showed the highest $\mathrm{CO}_{2}$ selectivity compared to sample prepared by coating [26]. The results obtained in the current study sustain the idea that $\underline{\text { an intimate contact between sepiolite fibres and } \mathrm{TiO}_{2}} \underline{\text { with }}_{\text {a corn-cob like structure improves }}$ TCE mineralization.

The scheme represented in Figure 8 illustrates the process taking place in the surface of the photocatalysts. At low $\mathrm{TiO}_{2}$ loading or thin $\mathrm{TiO}_{2}$ layer the intermediate species can easily migrate through the layer to the interface between the $\mathrm{TiO}_{2}$ and the substrate. Thus the reaction between intermediate products such as $\mathrm{COCl}_{2}$ and $\mathrm{OH}$ surface groups or adsorbed water molecules of the silicate can take place increasing TCE mineralization. On the other hand, when the $\mathrm{TiO}_{2}$ layer thickness increase, even if the TCE degradation rate is faster, the migration of these intermediate species is hindered by the long gap between the adsorbent and 
the catalytic surface where the reaction occurs. Consequently a decrease in TCE mineralization is observed. 


\section{Conclusions}

The results of this work evidence the key role of the support on the photocatalytic mineralization of TCE. This improvement accounts to its adsorption capability and the presence of $\mathrm{OH}^{-}$surface groups which are essential to carry out the trichloroethylene photocatalytic oxidation reaction. In spite of the direct relationship between $\mathrm{TiO}_{2}$ loadings and reaction rate, the $\mathrm{TiO}_{2}$ layer thickness has an important influence on the catalysts selectivity. When the distance between the external surface where the photocatalytic reaction tales place and the adsorbent increase, the diffusion of intermediates species is hindered, resulting in a pronounced decrease of the selectivity to $\mathrm{CO}_{2}$. It is in this interface where intermediate species react with $\mathrm{OH}$ groups of the support favouring TCE mineralization. In order to optimise the performance of coated hybrid photocatalysts several parameters have to be considered. Besides the factor related to the $\mathrm{TiO}_{2}$ physicochemical properties, the thickness of the layer plays an important effect on the selectivity of the process when hybrid photocatalysts are used. 


\section{References}

[1] O. Carp, C.L. Huisman, A. Reller, Prog. Solid State Chem. 32 (2004) 33.

[2]J.C. Yu, L. Zhang, Z. Zheng, J. Zhao, Chem. Mater. 15 (2003) 2280.

[3] Y. Chen, D.D. Dionysiou, Appl. Catal. B 80 (2008) 147.

[4] R. Portela, B. Sánchez, J.M. Coronado, R. Candal, S. Suárez, Catal. Today 129 (2007) 223.

[5] B. Herbig, P. Löbmann, J. Photochem. Photobio A: Chemistry 163 (2004) 359.

[6] N. Takeda, T. Torimoto, S. Sampath, S. Kuwabata, H. Yoneyama, J. Phys. Chem. 99 (24) (1995) 9986.

[7] L. Zou, Y. Luo, M. Hooper, E. Hu, Chem. Eng. Processing 45 (2006) 959.

[8] C. Ooka, H. Yoshida, K. Suzuki, T. Hattori., Appl. Catal. A 2004260 (1) 47.

[9] D. G. Shchukin, D. V. Sviridov, J.Photochem. Photobiol. C: Photochem. Rev. 7 (2006) 23.

[10] Y. Gao, H. Liu, Mater. Chem. Phys. 92 (2005) 604.

[11] H. Yoneyama, T. Torimoto, Catal. Today 58 (2000) 133.

[12] J. Blanco, A.L. Petre, M. Yates, M.P. Martin, S. Suárez, J.A. Martin, Adv. Mater. 189 (2006) 1162.

[13] A. Arques, A.M. Amat, L Santos-Juanes, R. F Vercher., M. Martín., A.J. Miranda, Molec. Catal. A 271 1-2 (2007) 221.

[14] R. Fernández-Saavedra, P. Aranda, E. Ruiz-Hitzky, Adv. Funct. Mater. 141 (2004) 77.

[15] S. Suárez, M. Yates, A.L. Petre, J.A. Martín, P. Avila, J. Blanco, Appl. Catal. B 64 3-4 (2006) 302 .

[16] P. Baeza, M. Villarroel, P. Avila, A.L. Agudo, B. Delmon, F.J. Gil-Llambias, Appl. Catal. A 304 (2006) 109.

[17] M.C. Lee, W. Choi, J. Phys. Chem. B 10645 (2002) 11818.

[18] H Haick, Y. Paz, J. Phys. Chem. B 10515 (2001) 3045.

[19] T. Tatsuma, S. Tachibana, T. Miwa, D.A. Tryck, A. Fujishima, J. Phys. Chem. B. 10338 (1999) 8033.

[20] M.R. Nimlos, W. Jacoby, D. M. Blake, T.A. Milne, Environ. Sci. Technol. 274 (1993) 732.

[21] S.H. Teichner, M. Formeti, Photoelectrochemistry, Photocatalysis and Photoreactors, Ed. M. Schiavello, D. Reidel: Dordrecht, Holland 1985, pp. 457-489. 
[22] J.F. Kenneke, J.L. Ferry, W.H. Glaze, Photocatalytic Purification and treatment of Water and Air; Eds. D.F. Ollis, H. Al-Ekabi, Elsevier Science Publishers, Amsterdam, 1993, p. 179. [23] L.A. Dibble, G.B. Raupp, catal. Lett. 4 (1990) 345.

[24] A.L. Pruden, D.F. Ollis, J. Catal. 82 (1983) 404.

[25] W.A. Jacoby, M.R. Nimlos, D. M. Blake, Environ. Sci. Technol. 28 (1994) 1661.

[26] S. Suárez, J.M. Coronado, R. Portela, J.C. Martín, M. Yates, P. Avila, B. Sanchez, Env. Sci. Tech. 42 (2008) 5892.

[27] J. Blanco, A. Romero, EP patent 0978313A1 (2000).

[28] J.M. Coronado, S. Suárez, P. Portela, B. Sanchez, J. Adv. Oxid. Tech. 112 (2008) 362.

[29] G.R. Hunt, Geophysics 423 (1997) 501.

[30] R.N. Clark, Chapter 1: Spectroscopy of Rocks and Minerals, and Principles of Spectroscopy, in Manual of Remote Sensing, Volume 3, Remote Sensing for the Earth Sciences, (A.N. Rencz, ed.) John Wiley and Sons, New York, p 3- 58, 1999.

[31] R.N Clark, T.V.V. King, M. Klejwa, G. Swayze, N. Vergo, J. Geophys. Res. 95 B8 (1990) 12653.

[32] D.M. Sherman, 1990. Crystal Chemistry, electronic structures and spectra of Fe sites in clay minerals. In: Coyne, L.M., McKeever, S.W.S., Drake, D.F. (Eds.), Spectroscopic Characterization of Minerals and their Surfaces. American Chemical Society, Washington DC, pp. 284-309.

[33] B. Sánchez, J. M. Coronado, R. Candal, R. Portela, I. Tejedor, M. A. Anderson, D. Tompkins, T. Lee, Appl. Catal. B 66 (2006) 295.

[34] W.A. Jacoby, D. M. Blake, R.D. Noble, C.A. Koval, J. Catal, 157 (1995) 87. 
Table 1. Characteristics of the coated photocatalysts

\begin{tabular}{|c|c|c|c|c|c|}
\hline & $\mathrm{N}^{\mathrm{o}}$ of coatings & $\begin{array}{l}{\left[\mathrm{TiO}_{2}\right]} \\
\text { wt.\% }\end{array}$ & $\begin{array}{l}\mathrm{TiO}_{2} / \text { area* } \\
\mathrm{mg} \mathrm{cm}^{-2}\end{array}$ & $\begin{array}{l}\text { Layer thickness } \\
\mu \mathrm{m}\end{array}$ & $\begin{array}{l}\text { Reflectance \% } \\
400 \mathrm{~nm}\end{array}$ \\
\hline $\mathrm{SiMgOx}$ & - & - & 0 & - & 29.6 \\
\hline $\mathrm{Si} / \mathrm{Ti}-1$ & 1 & 0.32 & 1.15 & 1 & 38.87 \\
\hline $\mathrm{Si} / \mathrm{Ti}-2$ & 2 & 0.55 & 1.95 & 3.8 & 43.2 \\
\hline $\mathrm{Si} / \mathrm{Ti}-3$ & 3 & 0.66 & 2.43 & 6.6 & 45.9 \\
\hline $\mathrm{Si} / \mathrm{Ti}-4$ & 4 & 0.75 & 2.64 & 10 & 50.0 \\
\hline $\begin{array}{c}\mathrm{TiO}_{2}-\mathrm{G} 5 \\
\text { fresh powder }\end{array}$ & - & $100 \%$ & - & - & 89.6 \\
\hline
\end{tabular}

* considering the surface covered by $\mathrm{TiO}_{2}$ (between 20.0 and $21.0 \mathrm{~cm}^{2}$ ) 


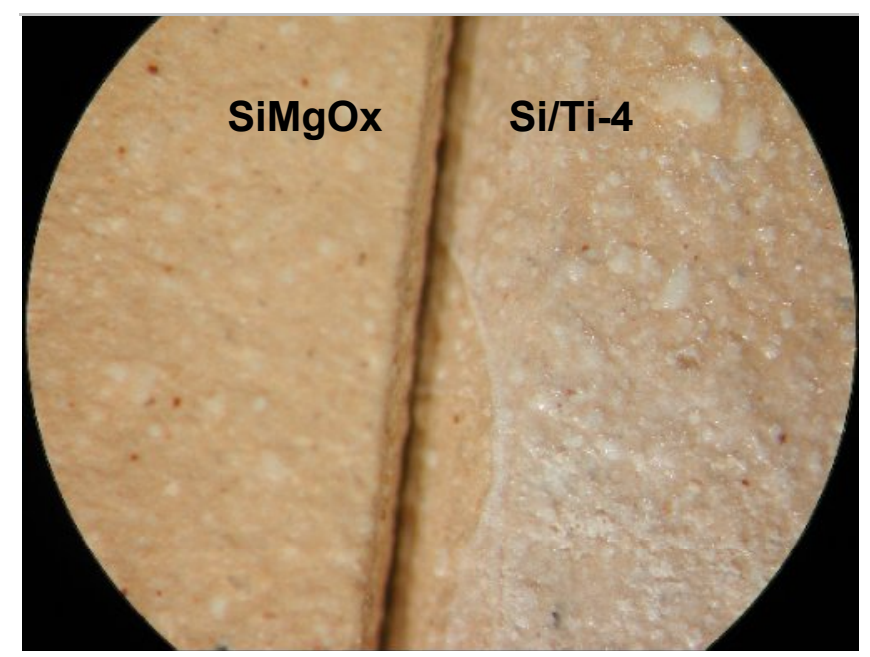

Figure 1. Photograph of magnesium silicate plate treated at $800^{\circ} \mathrm{C}$ and $\mathrm{Si} / \mathrm{Ti}-4$ hybrid photocatalysts with four layers of $\mathrm{TiO}_{2}$. 


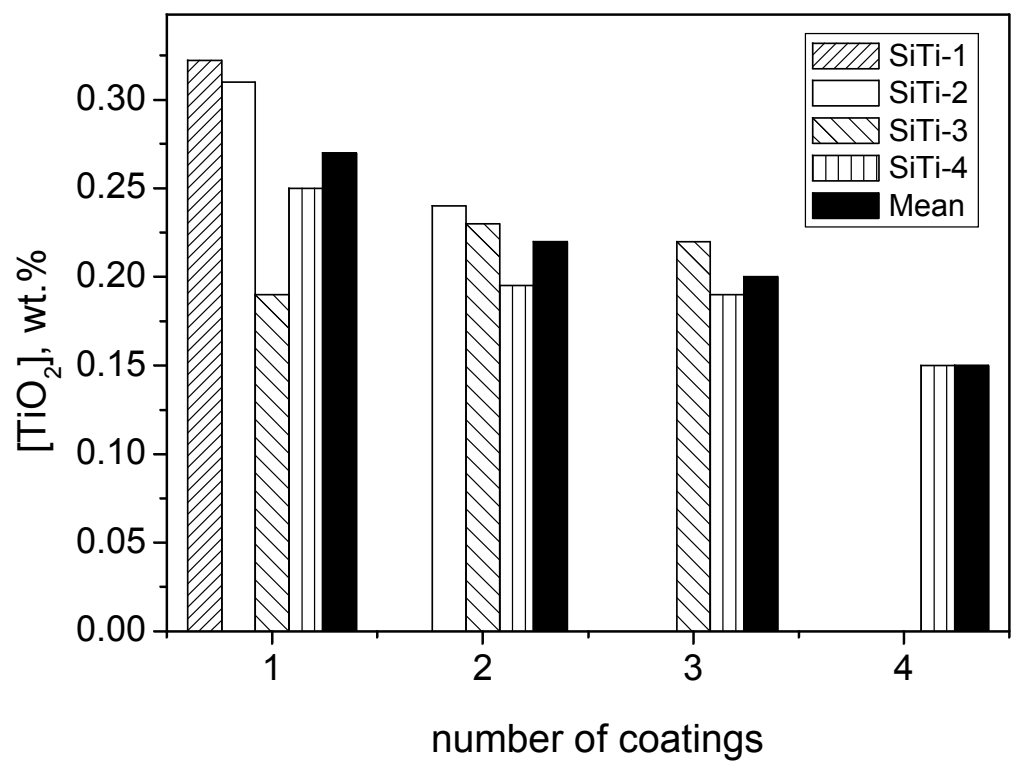

Figure 2. Variation of the amount of $\mathrm{TiO}_{2}$ deposited on the substrate with the number of layers. 


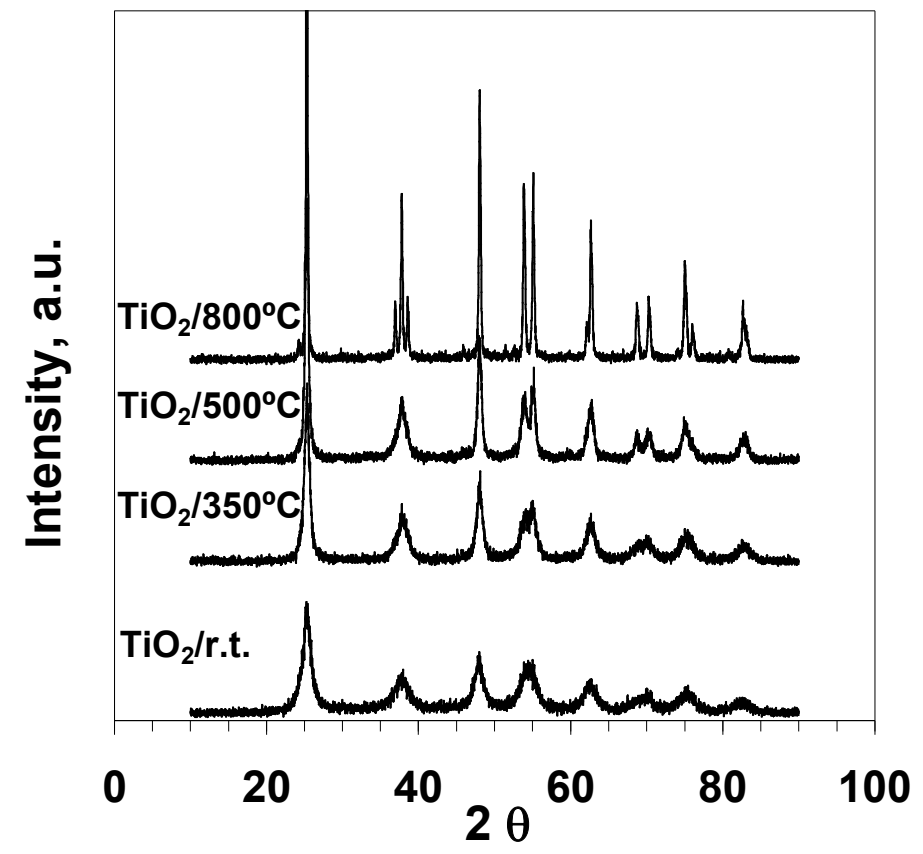

Figure 3. XRD diffractograms of $\mathrm{TiO}_{2} \mathrm{G}-5$ treated at different temperatures 

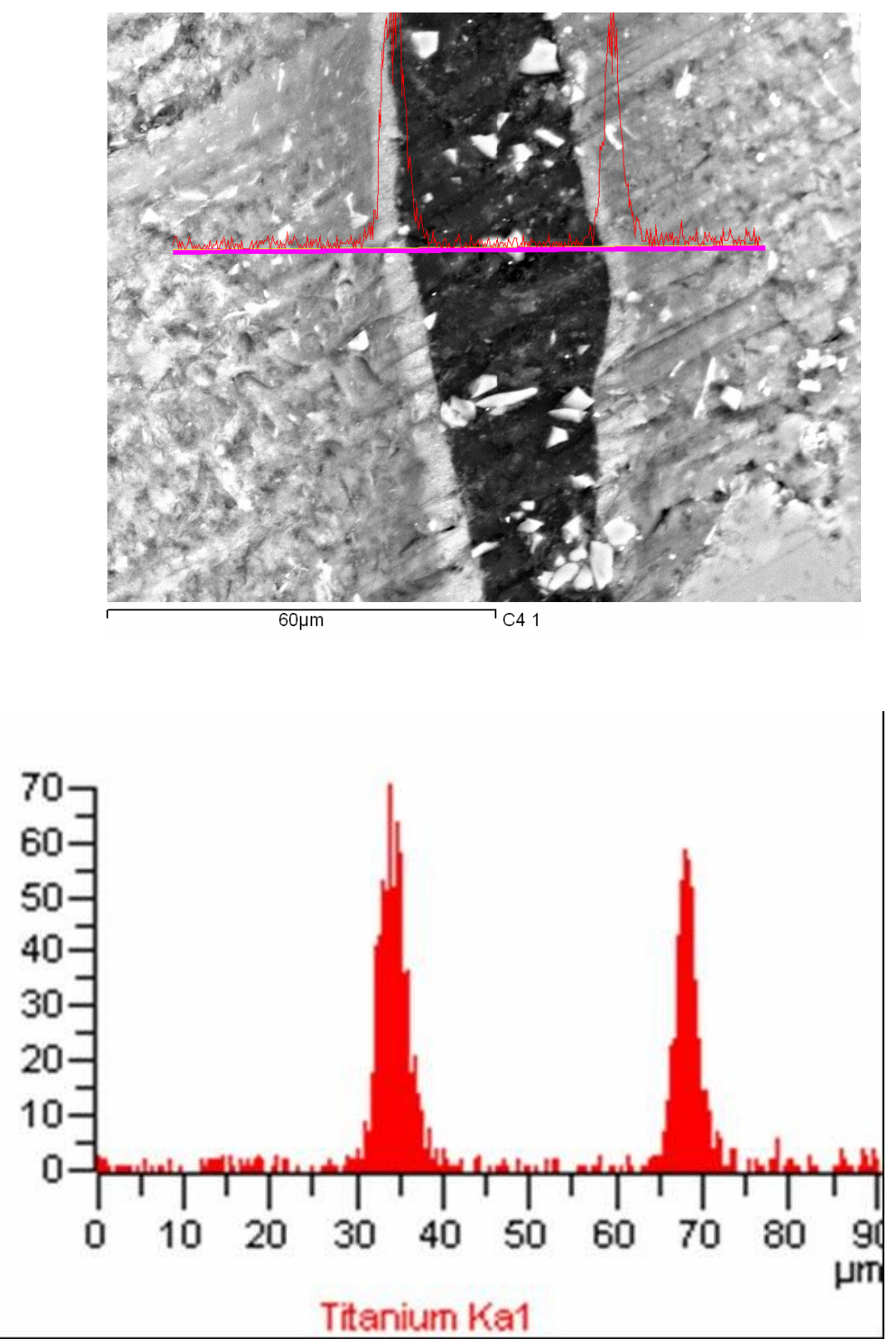

Figure 4. a) Micrograpy of a sandwich like structure cross section obtained by SEM, and b) Ti analysis obtained by XEDS form Si/Ti-4. 

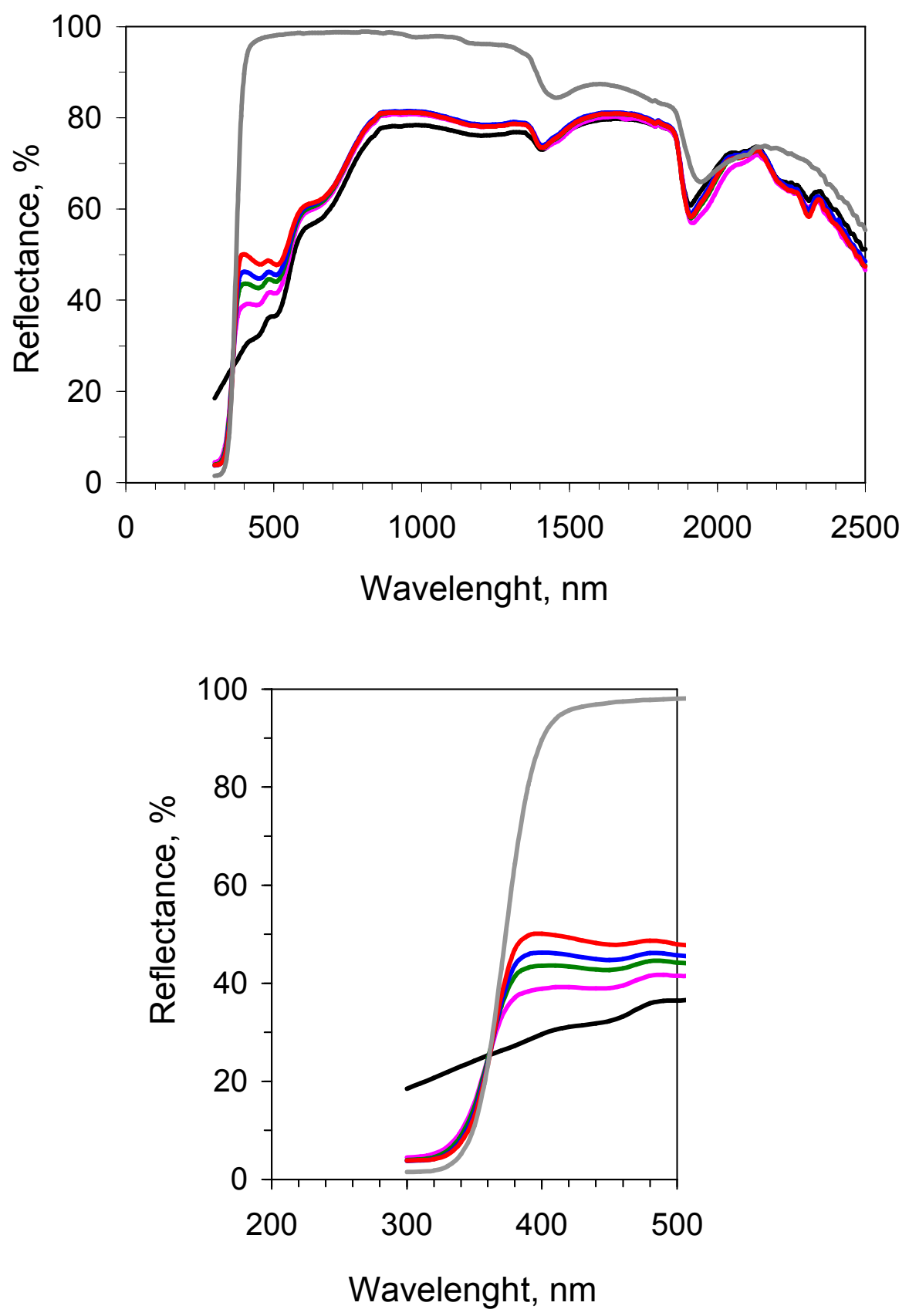

Figure 5. a) UV-vis spectra in the region between 300-2500 $\mathrm{nm}$ and b) Magnification of the region between $300-500 \mathrm{~nm}$ for the raw materials and coated samples: $\mathrm{TiO}_{2} \mathrm{G}-5$ r.t. (grey), SiMgOx (blanck), Si/Ti-1 (pink), Si/Ti-2 (green), Si/Ti-3 (blue), Si/Ti-4 (red). 

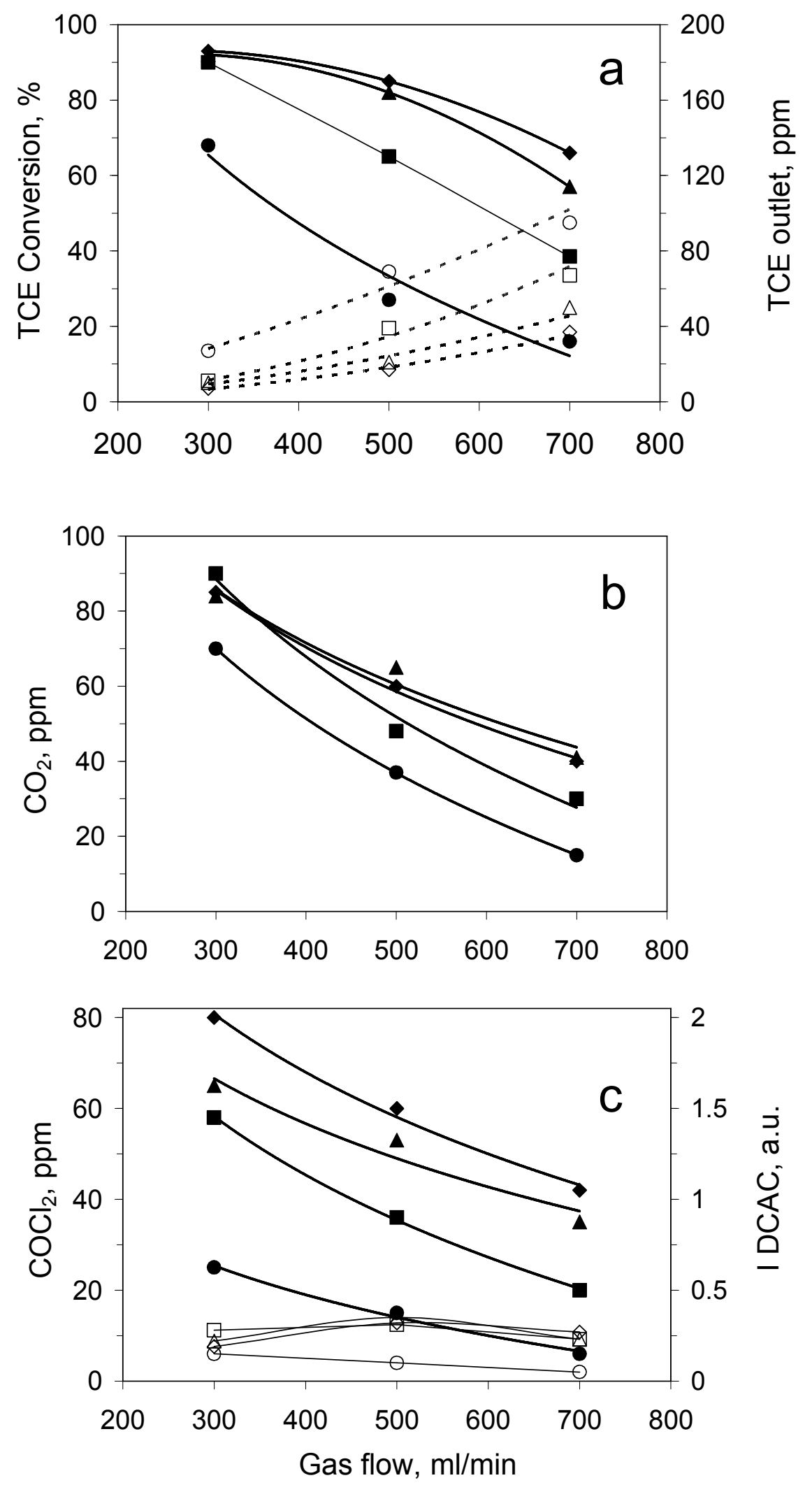

Figure 6. Photocatalytic degradation of TCE and concentration of reaction products : a) (filled symbols) TCE conversion and (open symbols) TCE amount, b) $\mathrm{CO}_{2} \mathrm{c}$ ) $\mathrm{COCl}_{2}$

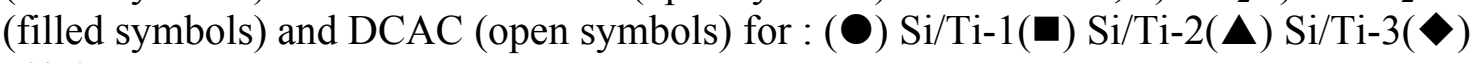
$\mathrm{Si} / \mathrm{Ti}-4$. 

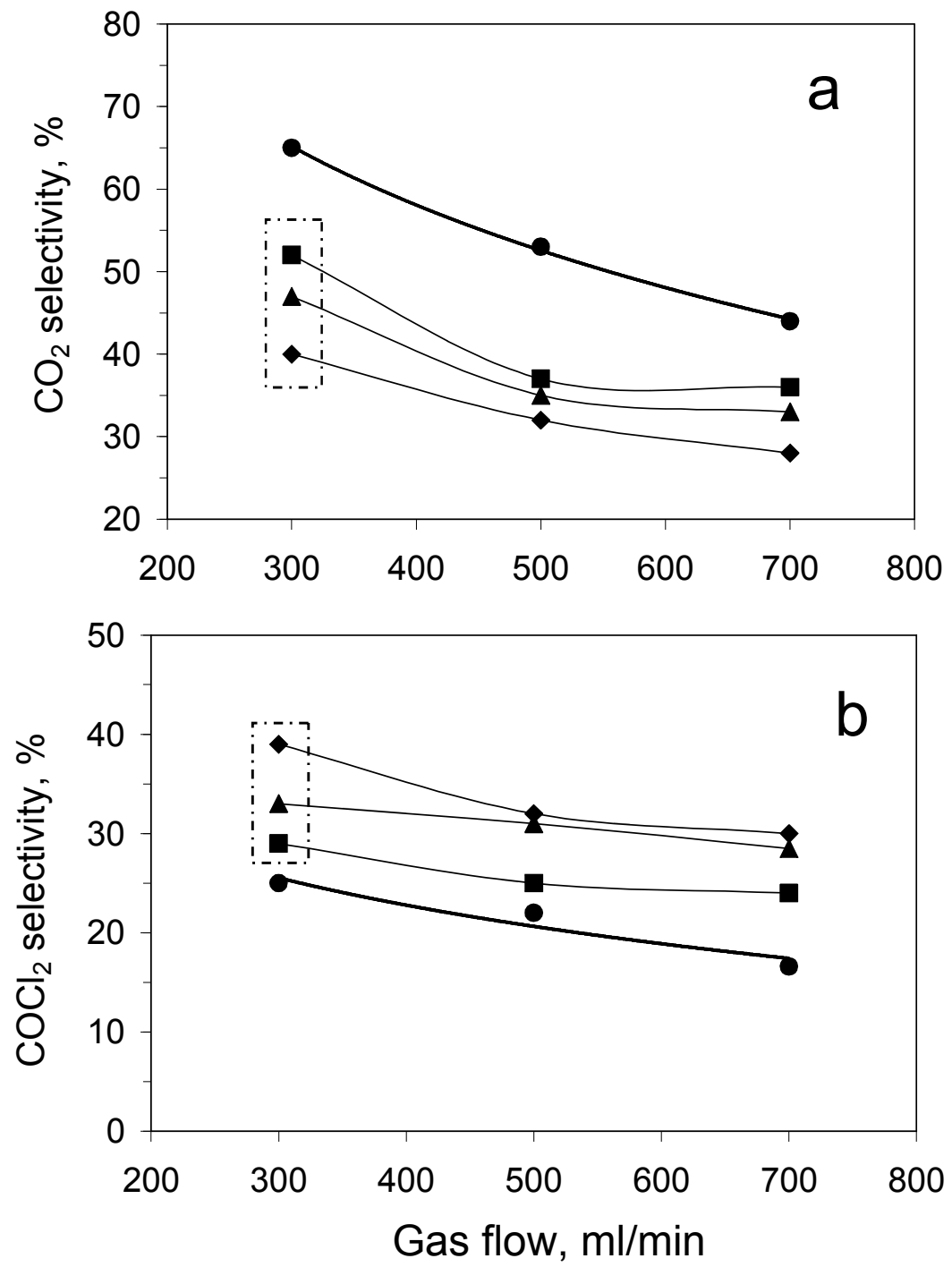

Figure 7. a) $\mathrm{CO}_{2}$ and b) $\mathrm{COCl}_{2}$ Selectivity in the TCE photodegradation reaction for:

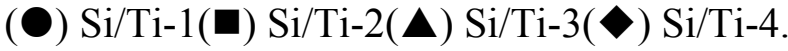


Figure 8. Schematic proposed for degradation of TCE on coated hybrid photocatalysts with different $\mathrm{TiO}_{2}$ layer thickness: (O) $\mathrm{TiO}_{2}$ photoactive particles and $(\square)$ sepiolite support.
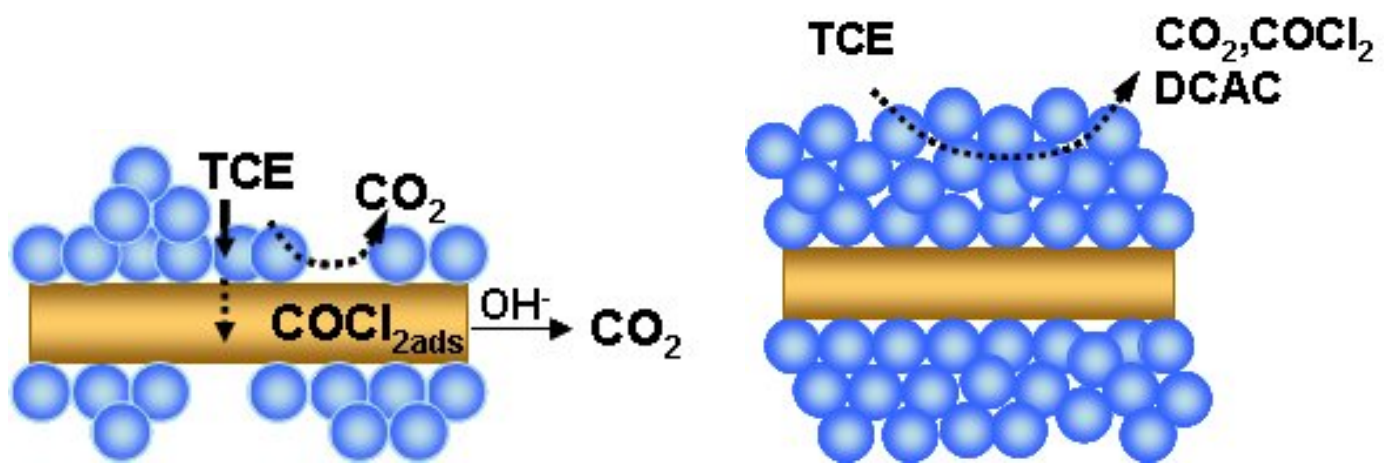